\title{
PEMBANGKIT LISTRIK TENAGA MINI HIDRO (PLTM) : PELUANG BAGI PARA PENGEMBANG BISNIS DAN TANTANGAN BAGI PARA PERANCANG TEKNOLOGI REKAYASA DI INDONESIA
}

\author{
Sirojuddin \\ Jurusan Teknik Mesin, Fakultas Teknik, Universitas Negeri Jakarta \\ e-mail : sirojuddinabbas@yahoo.com
}

\begin{abstract}
ABSTRAK
Menurut Statistik Energi Indonesia 2010 Ditjen Listrik dan Pemanfaatan Energi, potensi energi terbarukan di Indonesia untuk skala besar (>10 MW) sebesar 75GW kapasitas terpasang 4,2 $\mathrm{GW}$, untuk mini $(<10 \mathrm{MW}) /$ mikrohidro potensi $450 \mathrm{MW}$ terpasang $84 \mathrm{MW}$. Potensi yang ada merupakan peluang besar bagi para pengembang bisnis karena pembelinya jelas yaitu PLN, BEP setelah konstruksi rata-rata 5 tahun dengan IRR 18-23\%. Bagi para perancang teknologi rekayasa ini merupakan tantangan untuk mengembangkan pengetahuan, keahlian secara praktis dalam bidang teknik mesin, sipil, elektrolelektronika, geoteknik, geodesi, metalurgi maupun manajemen proyek. Perancangan meliputi : penyiapan data, proses data, konsep desain, optimasi desain, detail desain dan pengawasan desain.
\end{abstract}

Kata kunci : Energi terbarukan, PLTM, Pengembang Bisnis, Perancang Teknologi Rekayasa

\section{PENDAHULUAN}

Energi terbarukan (Renewable Energy) adalah energi yang dapat diperbaharui, masuk dalam kategori ini adalah : air, matahari, angin, panas bumi, biomass. Berbeda dengan energi fosil (batu bara, minyak bumi, gas alam), energi terbarukan bersifat ramah lingkungan, cenderung tak terbatas, tidak memberikan efek gas rumah kaca (Gree House Gases) dan tidak memberikan kontribusi terhadap perubahan iklim dan potensi pemanasan global ${ }^{[1]}$.

Menurut Indonesia Energi Outlook 2010 dan Statistik Ekonomi Energi Indonesia 2004 potensi energi terbarukan di Indonesia sebagai berikut ${ }^{[2,3]}$ :

\begin{tabular}{|l|l|r|}
\hline $\begin{array}{c}\text { ENERGI } \\
\text { TERBARU }\end{array}$ & \multicolumn{1}{c|}{$\begin{array}{c}\text { KAP. } \\
\text { KERPASA } \\
\text { NG }\end{array}$} \\
\hline Tenaga Air & $75,67 \mathrm{GW}$ & $4200 \mathrm{MW}$ \\
\hline Panas Bumi & $27 \mathrm{GW}$ & $807 \mathrm{MW}$ \\
\hline $\begin{array}{l}\text { Mini/Mikro } \\
\text { Hidro }\end{array}$ & $712 \mathrm{MW}$ & $206 \mathrm{MW}$ \\
\hline Biomass & $49,81 \mathrm{GW}$ & $445 \mathrm{MW}$ \\
\hline $\begin{array}{l}\text { Energi } \\
\text { Surya }\end{array}$ & $\begin{array}{l}4,8 \mathrm{kWh} / \mathrm{m} 2 \\
/ \text { hari }\end{array}$ & $8 \mathrm{MW}$ \\
\hline $\begin{array}{l}\text { Energi } \\
\text { Angin }\end{array}$ & $3-6 \mathrm{~m} / \mathrm{det}$ & $0,6 \mathrm{MW}$ \\
\hline
\end{tabular}

Dari data tersebut potensi Pembangkit Lstrik Tenaga Air skala besar (>10 MW) sebesar kurang lebih $75 \mathrm{GW}$, terpasang hanya 4,2 GW sedang untuk skala kecil <10 
MW (PLTM/PLTMH) potensi $712 \mathrm{MW}$, terpasang $206 \mathrm{MW}$.

Pembangkit listrik skala besar umumnya dihandel

oleh pemerintah karena biaya dan permasalahannya

Pembangkit listrik skala besar umumnya

dihandel oleh pemerintah karena biaya dan

permasalahannya

sangat besar, sedang pembangkit skala kecil dapat dilakukan oleh swasta maupun perguruan tinggi.

Sehubungan dengan PLTM akan dibahas 2 hal :

1. Peluang bagi Pengembang

Bisnis

2. Tantangan bagi Perancang

Teknologi Rekayasa.

\section{PELUANG BAGI PENGEMBANG BISNIS}

Untuk menjalankan bisnisnya pengembang bisnis selalu melihat berapa profit yang akan diperoleh, berapa lama Break Even Pointnya (BEP), berapa persen IRR nya , berapa lama umur proyek . Untuk itu diperlukan kepastian pembeli, lamanya perjanjian kontrak pembelian (Power Purchase Agreement) , faktor resiko dan lain-lain.

Menurut Permen ESDM Nomor : 05 Tahun 2009, PT PLN (Persero) wajib melakukan pembelian tenaga listrik yang menggunakan sumber energi terbarukan dengan kapasitas sampai dengan 10 MW sesuai dengan ketentuan peraturan perundang-undangan ${ }^{[4]}$ dan Permen ESDM Nomor : 31 tahun 2009 pasal 2 harga pembelian listrik Rp 656/kWh x $\mathrm{F}$ [5], jika terinterkoneksi pada Tegangan Menengah (JTM) dan Rp 1.004/kWh x F, jika terinterkoneksi pada tegangan Rendah (JTR). F adalah factor insentip sesuai dengan lokasi pembelian oleh PT PLN, dengan besaran sebagai berikut : a. Wilayah Jawa dan Bali, $F=1$

b. Wilayah Sumatera dan Sulawesi, F= 1,2

c.Wilayah Kalimantan, Nusa Tenggara Barat dan Nusa Tenggara Timur, F = 1,3

d. Wilayah Maluku dan Papua, $F=1,5$

Studi kelayakan ${ }^{[4,5]}$ menunjukkan bahwa dengan capacity factor pembangkitan listrik sebesar $70 \%$ tariff dasar pembelian oleh PT PLN Rp 656/kWh memperoleh IRR > $20 \%$, Payback Period 5-6 tahun, sehingga investasi pembangunan PLTM layak secara ekonomi dan teknis

\section{PEMBANGKIT LISTRIK TENAGA MINI HIDRO (PLTM)}

Untuk membangun sebuah PLTM diperlukan proses survey, pengurusan izinizin, penyiapan dan proses data, pembebasan lahan, penyiapan konsep , optimasi dan detail desain, penyiapan dana, manajemen konstruksi selanjutnya pembangunan dan pengawasan. Pengawasan meliputi bidang konstruksi dan desain yang telah dibuat.

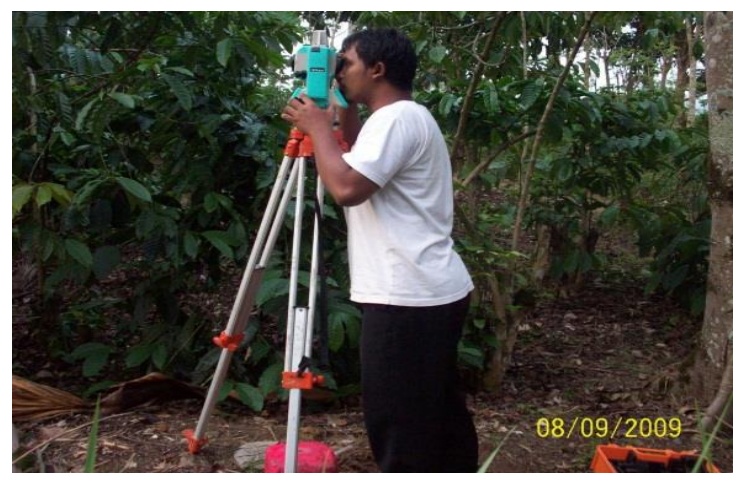

Gambar 1.: Survey Pengukuran

\subsection{Apa beda PLTM dan PLTA ?}

Secara sederhana perbedaan PLTM dan PLTA dan bagaimana cara kerjanya, dapat dilihat dari gambar di bawah ini : 


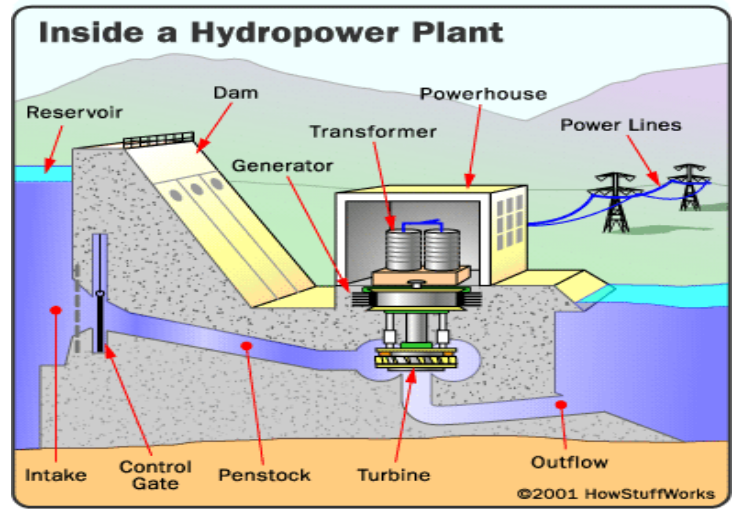

Gambar 2 : PLTA besar menggunakan Bendungan.

\section{Sumber}

www://howstuffworks.com

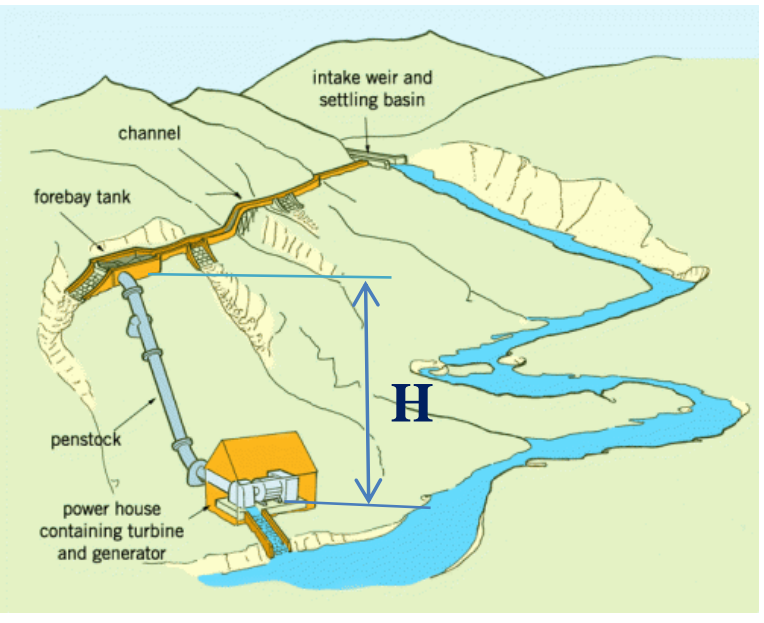

Gambar 3 : Lay Out PLTM

\section{Sumber:http://cgienergy.com/gbr/mh.jpg}

Bagian-bagian utama yang terdapat pada suatu PLTM :

1. Bendung atau Weir

2. Intake

3. Kolam Pengendap Sedimen

4. Saluran Pembawa

5. Kolam Penenang

6. Penstock (pipa pesat)

7. Rumah Pembangkit (Power House)
8. Turbin dan Generator

9. Tail Race

\subsection{Hidrologi}

Untukmerancang sebuah PLTM diperlukandata hidrologi. Hidrologi Adalah suatu ilmu yang mempelajari air dibumi, kejadian, sirkulasi dan distribusi, sifat-sifat kimia dan fisika dan reaksinya dengan lingkungan, termasuk hubungannya dengan mahkluk hidup ${ }^{[6]}$

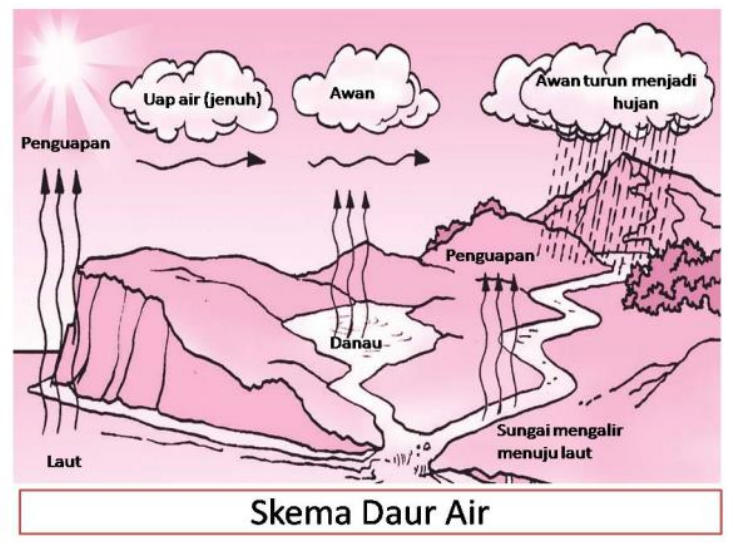

Gambar 3 : Skema Daur Air

Sumber : http://sopiyudin11.blogspot.com

Data hidrologi diperoleh dari Badan Meteorologi dan Geofisika, Lembaga Perkebunan ataupun Direktorat Pengelolaan Masalah Air (DPMA). Data berupa curah hujan harian, penyinaran, penguapan dan kecepatan angin selama 1 sampai 20 tahun lebih.

\subsubsection{Debit Air}

Faktor ketersediaan aliran air sepanjang tahun sangat penting bagi kelangsungan suatu PLTM. i . Ada 2 data debit aliran air , yang pertama adalah data primer dan yang 
kedua adalah data sekunder. Data primer diperoleh bila sungai dilakukan pengukuran dengan alat AWLR (Automatic Water Level Record) selama bertahun-tahun, minimal 10 tahun, sedang data sekunder diperoleh dengan mengolah data hidrologi yang ada minimal 10 tahun penuh.

\subsubsection{Data untuk Desain}

Baik data primer maupun data sekunder akan memperoleh Kurva Durasi Aliran selama minimal 10 tahun, ProsentaseKetersediaan Air,, Debit ratarata, Debit Andalan (Debit Desain), Debit Banjir 5, 10, 15, ...., 50 sampai 100 tahun. Data inilah yang akan dipakai nantinya untuk mendesain suatu PLTM. Di Indonesia umumnya sangat sulit untuk mendapatkan data primer sehingga sering digunakan data sekunder.

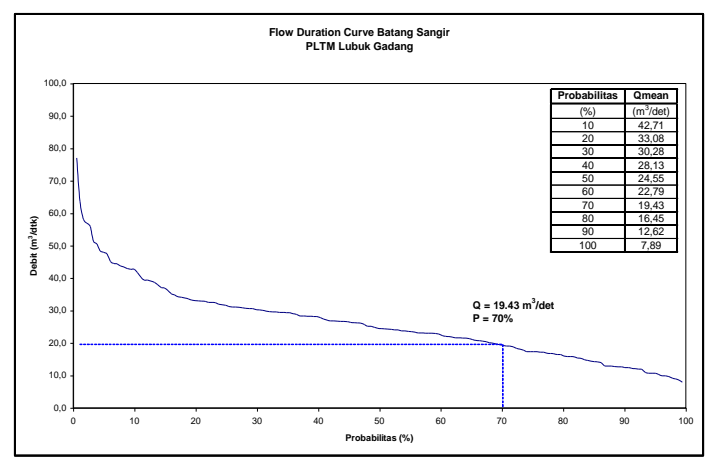

Gambar 4 : Kurva Durasi Debit

\subsection{Data Geologi dan Geoteknik}

Data geologi meliputi data batuan, jenis-jenis tanah, data gempa, dan lainlain. Data geoteknik dibutuhkan untuk memperoleh sifat-sifat fisis dan mekanis tanah

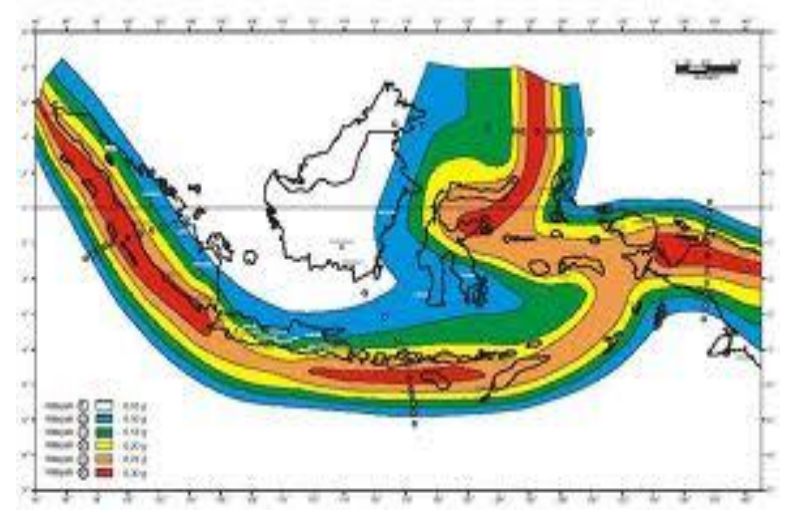

Gambar 5 : Jalur Gempa di Indonesia

Sumber :http://epentcyrrus.blogspot.com

\subsection{Daya yang Dibangkitkan}

Berdasarkan data debit andalan dapat dihitung daya yang dibangkitkan oleh suatu PLTM sebagai berikut :

Persamaan umum :

$$
\begin{aligned}
& \mathbf{P}=\mathbf{m} / \mathbf{s} . \quad \text { g. } \quad \mathbf{H} \\
& \text { (1) } \\
& \text { dimana }: \mathrm{P}=\operatorname{Daya}(\mathrm{W}) \\
& \mathrm{m} / \mathrm{s}=\mathrm{massa} / \operatorname{det} \mathrm{ik}(\mathrm{kg} / \text { detik }) \\
& \mathrm{g}=\operatorname{gravitasi}\left(\mathrm{m} / \mathrm{dt}^{2}\right) \\
& \mathrm{H}=\mathrm{Head} / \text { tinggi jatuh }(\mathrm{m})
\end{aligned}
$$

Persamaan aktual :

$$
P_{g} \doteq \dot{m} \cdot g \cdot\left(H_{G}-H_{L}\right) \cdot \eta_{T} \cdot \eta_{g} \cdot 10^{-3}
$$

$P_{g}$ adalah daya yang keluar dari generator

(kW) $m$ Aliran massa per detik (kg/det), $g$ gravitasi $\left(\mathrm{m} / \mathrm{det}^{2}\right), H_{G}$ tinggi jatuh kotor 
( m), $H_{L}$ Head Losses (mayor, minor, dll ) (m), $\quad \eta_{T} \quad$ Effisiensi turbin ( \%), $\eta_{g}$ Effisiensi Generator $(\%)$.

\subsection{PEMILIHAN TURBIN}

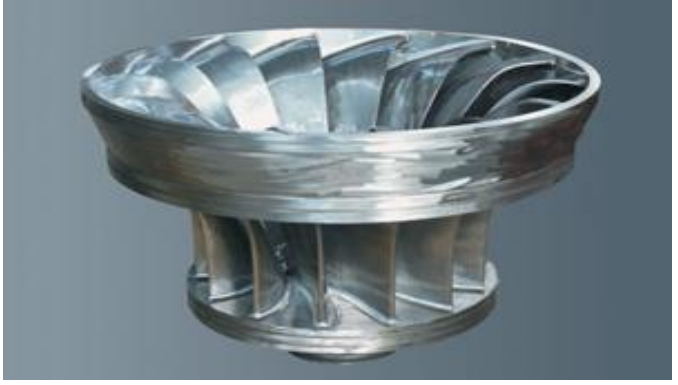

Gambar 6 : Runner Turbin Francis

Sumber ; SHZ turbine China

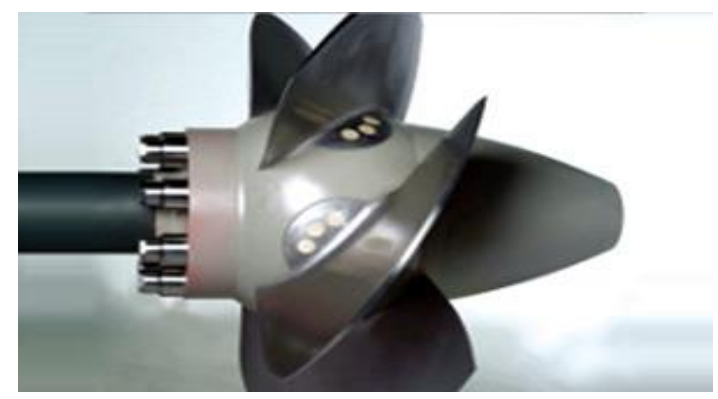

Gambar 6 : Runner Turbin Kaplan

Sumber ; SHZ turbine China

Turbin berfungsi menerima energi potensial dari aliran air sebesar $\mathrm{Q}$ yang jatuh dengan ketinggian $\mathrm{H}$ berubah menjadi energi kinetis, kemudian diubah menjadi energy mekanis dalam bentuk putaran selanjutnya menggerakkan generator untuk menghasilkan listrik. Jenis turbin untuk PLTM dan PLTA biasanya : Francis, Kaplan dan Pelton.Untuk kapasitas kecil PLTMH biasanya : Turgo,
Banki, Crossflow. Untuk menentukan jenis turbin dapat dipakai diagram dibawah ini. Contoh : bila $\mathrm{Q}=5 \mathrm{~m} 3 /$ det dengan $\mathrm{H}=90 \mathrm{~m}$ diperoleh jenis turbin Francis dengan daya $3000 \mathrm{~kW}$. Karena pertimbangan operasi digunakan 2 turbin masing-masing $1500 \mathrm{~kW}$.

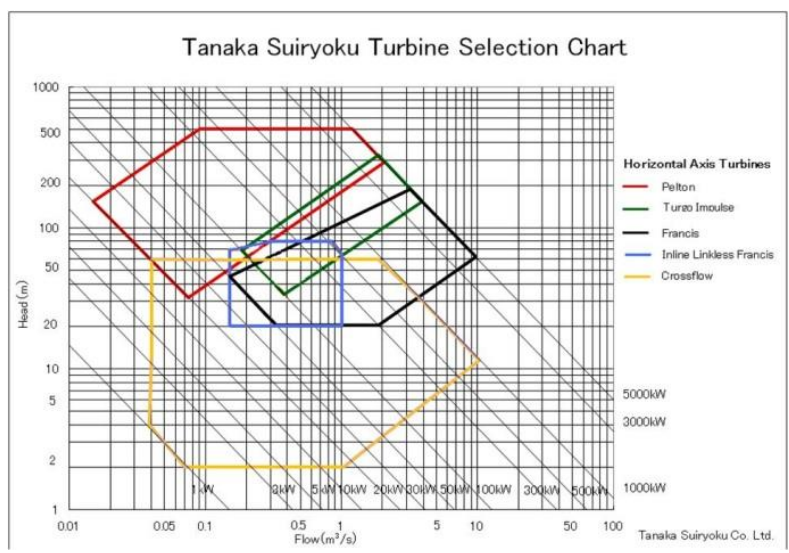

Gambar 7 : Diagram Pemilihan Turbin

Sumber:http://www.tanasui.co.jp/productsch arts.html

Umumnya turbin dipesan kepada pabrik pembuat, adapun data-data effisiensi, putaran, flywheel effect akan diberikan dari pabrikan. Perancang teknologi harus memperhatikan berapa besar flywheel effect yang dibutuhkan agar turbin stabil pada kondisi listrik LOAD dan NO LOAD.

\subsection{DESAIN STRUKTUR SIPIL}

Perancangan bangunan sipil untuk PLTM dapat mengikuti buku Standar Perencanaan Irigasi yang dikeluarkan oleh Departemen PU DirektoratJendral Pengairan mulai dari Bendung sampai Kolam Penenang.Bangunan ini umumnya dilakukan uji model hidrolis (Model Test) dulu sebelum diterapkan di lapangan, tujuannya untuk melihat keakuratan desain 
dengan karakteristik aliran air mulai dari aliran normal samoai aliran saat banjir. Secara umum bentuk-bentuk bangunan sipil pada PLTM adalah sebagai berikut :

\subsubsection{BENDUNG}

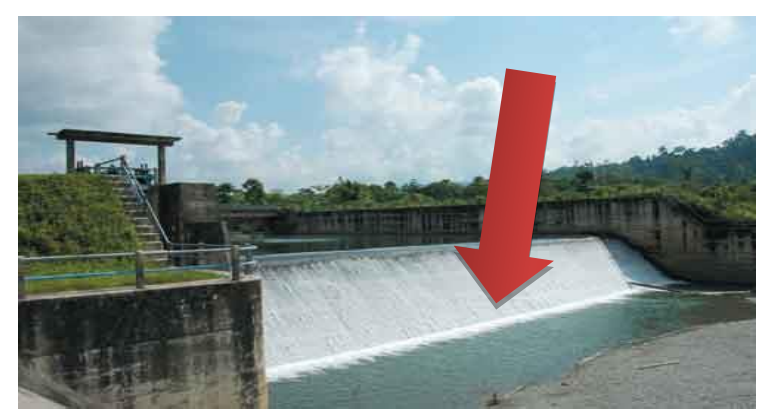

Gambar 8 : Bendung

Sumber :http://pustaka.pu.go.id

\subsubsection{INTAKE}

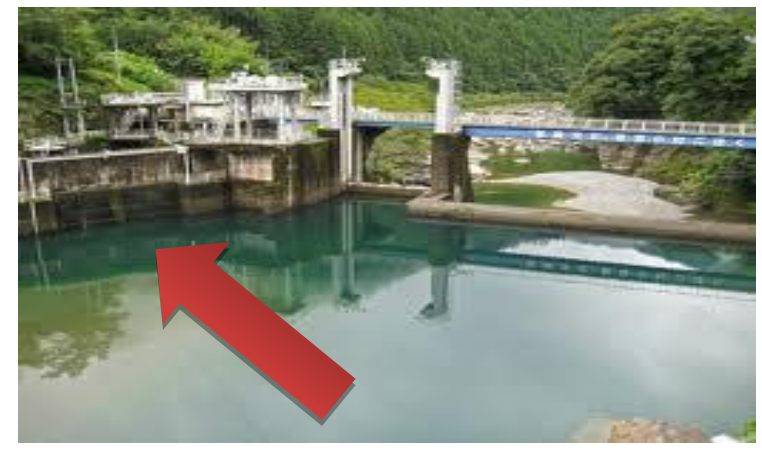

Gambar 9 : Intake

Sumber : http://commons.wikimedia.org

\subsubsection{KOLAM PENGENDAP SEDIMEN}

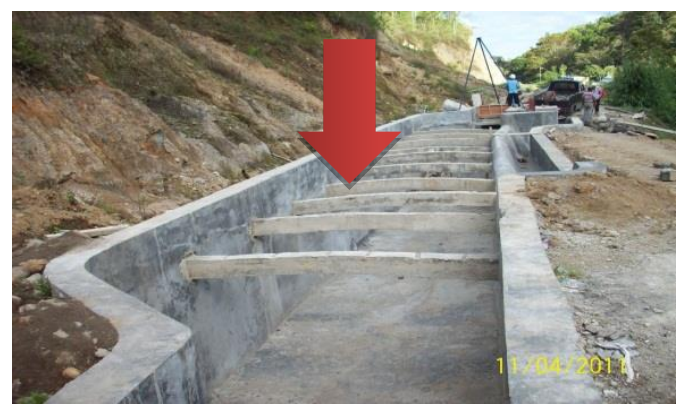

Gambar 10 : Kolam Pengendap Sedimen

Sumber : PLTM NAPAL MELINTANG ENERGI

\subsubsection{SALURAN PEMBAWA}

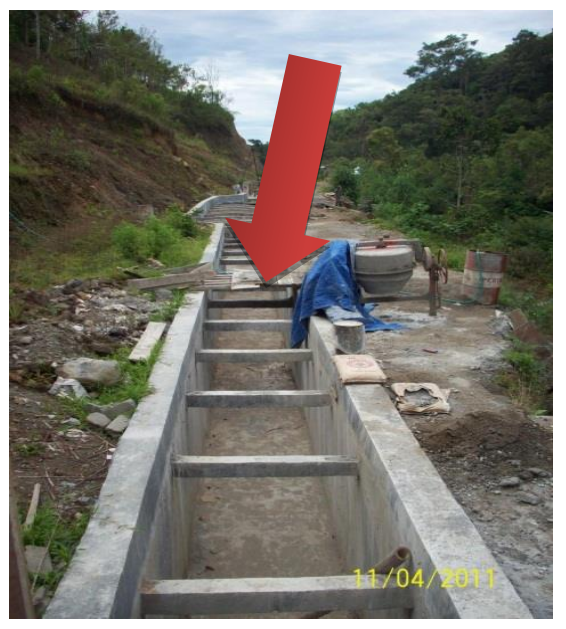

Gambar 11 : saluran Pembawa

Sumber : PLTM NAPAL MELINTANG ENERGI 


\subsubsection{KOLAM PENENANG}

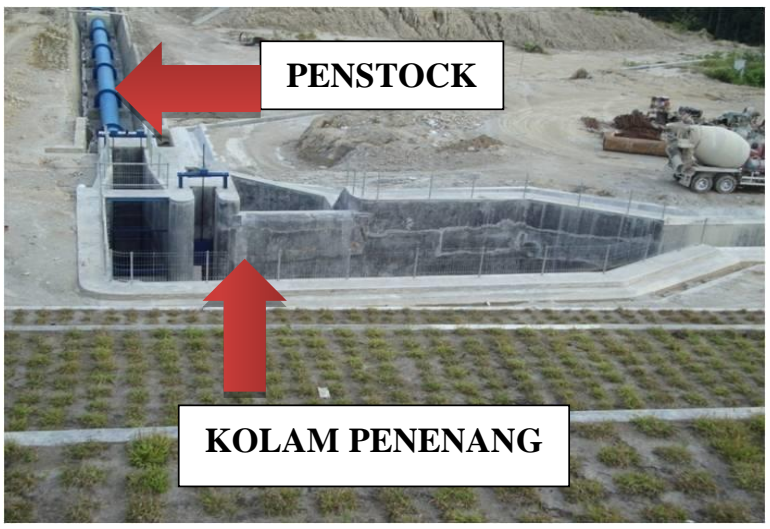

Gambar 12 : KolamPenenang (Head Pond)

Sumber :http://adhiproject.wordpress.com

\subsection{HIDROMEKANIKAL}

\subsubsection{PENSTOCK}

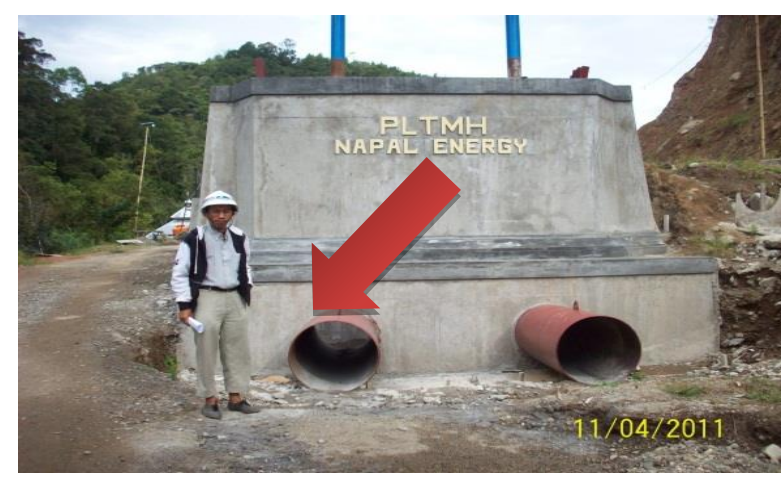

Gambar 13 : Keluaran Penstock dari Kolam Penenang

\section{Sumber : PLTM NAPAL MELINTANG ENERGI}

Ada 2 tipe penstock : 1) diatas permukaan 2) terbenam. Penstock berfungsi menyalurkan air dari kolam penenang menuju turbin setinggi $\mathrm{H}$ dan menahanterjadinya water hammer (pukulan air) saat pintu turbin ditutup mendadak.

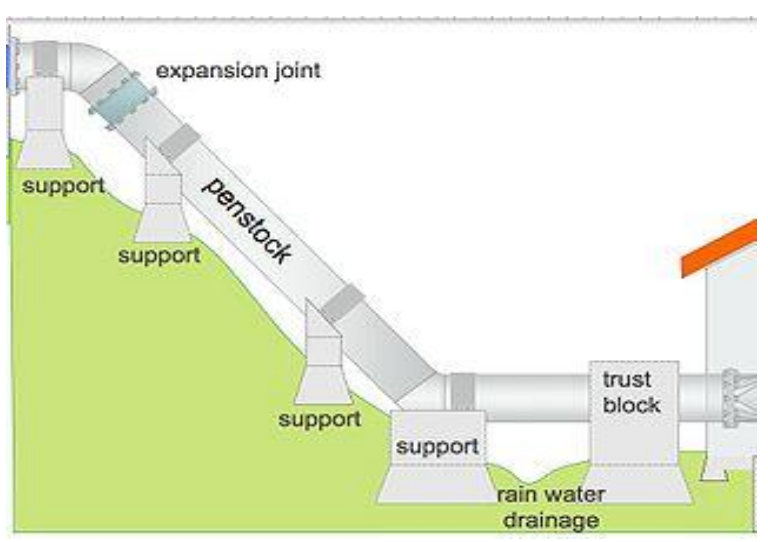

\section{Gambar 14 : Penstock}

Sumber :http://energypedia.info

Berdasarkan persamaan Manning ${ }^{[9]}$ :

$$
\frac{h f}{L}=10,3 \frac{n^{2} Q^{2}}{D^{5,333}}
$$

Hf adalah total losses sepanjang penstock (m) , L panjang penstock (m), n konstanta Kutte atau Manning tergantung jenis bahan, $\mathrm{Q}$ debit desain (m), D diameter optimum (m).

Bila hf dibatasi sampai $4 \% \mathrm{H}$ sehingga diperoleh diameter optimum [7]:

$D=2,69\left(\frac{10,3 n^{2} Q^{2} L}{h_{f}}\right)^{0,1875}$

Tebal minimum untuk handling ${ }^{[9]}$ :

$t_{\text {min }}=\left(\frac{D+508}{400}\right), \ldots \mathrm{mm}$

Tebal penstock didesain berbeda-beda pada tinggi dan panjang tertentu ${ }^{[9]}$ : 
$t=\frac{P D}{2 \sigma_{a} \eta}+C A(6)$

$\mathrm{P}$ adalah tekanan hidrostatis akibat water hammer $(\mathrm{kN} / \mathrm{mm} 2)$, D diameter penstock $(\mathrm{mm}), \sigma_{\mathrm{a}}$ Tegangan izin bahan $(\mathrm{kN} / \mathrm{mm} 2), \eta$ effisiensi las.

Tekanan akibat water hammer dihitung dengan persamaan ${ }^{[9]}$ :

$\mathrm{P}=\mathrm{Po}+\Delta \mathrm{P}$

$\nabla P=P o\left[\frac{N}{2} \pm\left(\frac{N^{2}}{4}+N\right)^{1 / 2}\right]$

$N=\left(\frac{L V}{g P_{o} t}\right)^{2}$

$\mathrm{V}$ adalah kecepatan air $(\mathrm{m} / \mathrm{det}), \mathrm{L}$ total panjang penstock (m), Po Tekanan hidrostatis kotor $(\mathrm{m})$, $\mathrm{t}$ waktu menutup (det).

Selanjutnya dihitung pula tegangan temperature, Tegangan longitudinal akibat regangan radial, beam stress $[10]$.

Tegangan kombinasi diperoleh dengan rumus Von Mises-Hencky ${ }^{[11]}$ :

$\sigma_{e}=\sigma_{c o}=\left(\sigma_{x}^{2}+\sigma_{y}^{2}-\sigma_{x} \sigma_{y}+3 \tau_{x y}^{2}\right)^{1 / 2}$

$\operatorname{Dimana} \sigma_{c o} \leq \sigma_{a}$

\subsection{RUMAH PEMBANGKIT (POWER HOUSE)}

Power house atau rumah pembangkit berfungsi sebagai tempat turbin $\&$ generator, panel kontrol, ruang kontrol, alat pengangkat oan kontrol-kontrol lainnya.

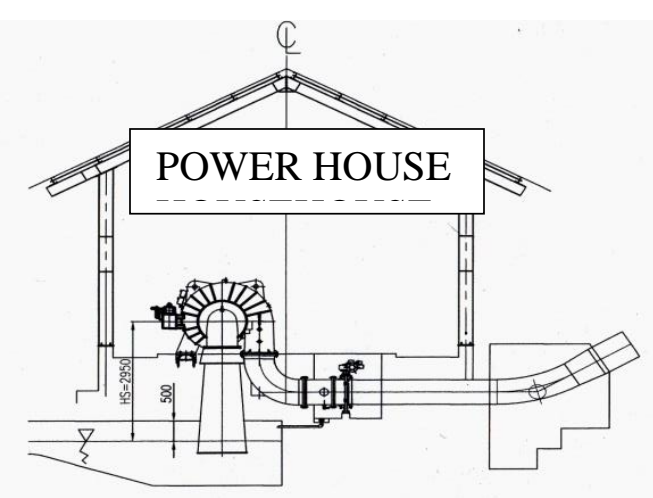

\section{Gambar 15 : Power House}

\subsubsection{Stabilitas Turbin}

Kestabilan turbin dan generator dihitung berdasarkan rumus berikut ${ }^{[12]}$ :

$5>\frac{T m}{T w}>4(11)$

Tm = Machine Time Constant (detik)

$\mathrm{Tw}=$ Water Time Constant $($ detik $)$

dimana $: \operatorname{Tm}=\left\{\left(\mathrm{GD}^{2} . \mathrm{n}\right) /(367 . \mathrm{P})\right\}$

$\mathrm{GD}^{2}$ adalah Efek roda gi; a bagian yang bergerak (flywheel effect) (ton.m ${ }^{2}$ ), $\mathrm{n}=$ putaran turbin $(\mathrm{rpm}), \mathrm{P}$ daya turbin $(\mathrm{kW})$.

$T w=\frac{\sum L V}{g H}$

$\mathrm{Tw} \leq 2,5$ detik 
$\mathrm{L}$ adalah panjang penstock $(\mathrm{m}), \mathrm{V}$ kecepatan air dalam penstock (m/det), $\mathrm{H}$ net head $(\mathrm{m})$.

Stabilitas turbin mempengaruhi kepekaan putaran pada saat NO LOAD dan LOAD, sebab apabila putaran berubah frekwensi listrik akan berubah. Bila besaran nilai fywheel effect belum cukup maka dapat diusulkan kepabrikannya .

\subsubsection{Tinggi Hisap (Suction Head) Draft Tube Turbin}

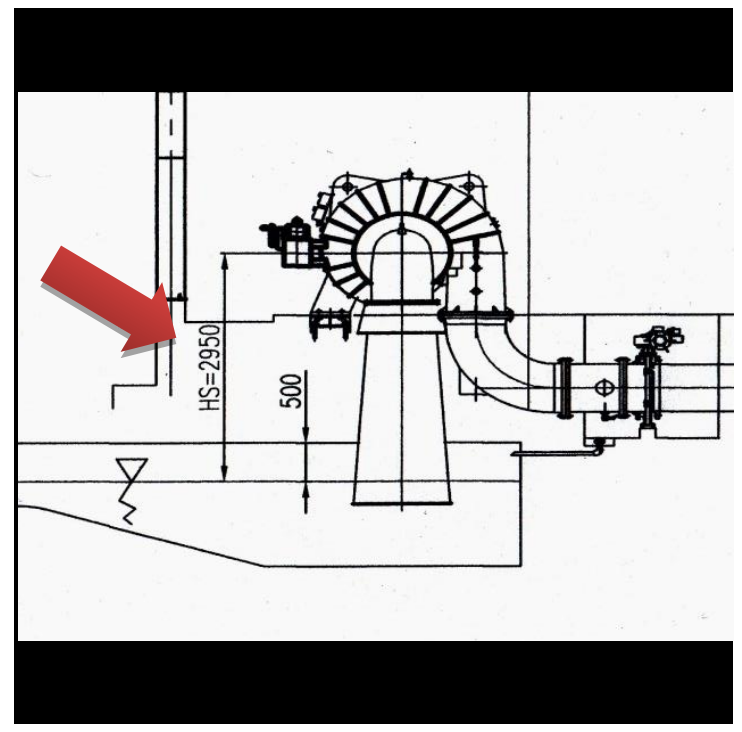

\section{Gambar 16 : Draft Tube Turbin}

Untuk menghindari terjadinya kavitasi maka perlu dihitung tinggi hisap muka air draft tube terhadap center turbin.[7]

$H s=10,3-\frac{\nabla}{900}-\sigma_{P} . H(14)$

Hs adalah suction head (m), $\nabla$ ketinggian turbin diatas permukaan laut $(\mathrm{m}), \sigma_{P}$ factor kavitasi (Thoma )plant, $\mathrm{H}$ gross head (m).

$\sigma_{P}=(1,2-1,4) \sigma_{c}$ $\sigma_{c}=$ Thoma Critical

\subsection{Tail Race}

Tail Race adalah saluran air keluar dari draft tube turbin untuk dikembalikan masuk sungai kembali.

Tail race didesain sedemikian rupa agar bila terjadi variasi debit air tidak terjadi kavitasi dan saat sungai banjir air tidak masuk ke power house atau turbin.

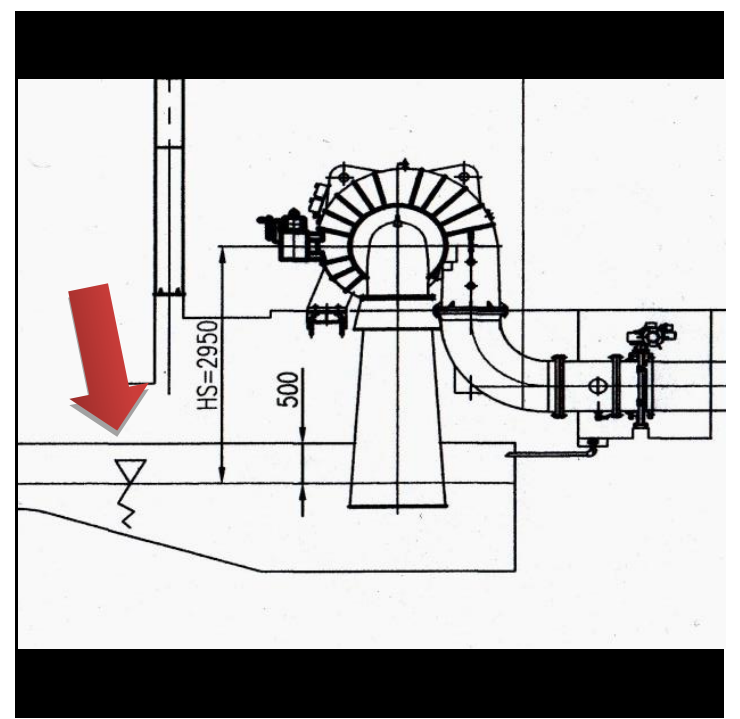

Gambar 17 : Tail Race

\section{KESIMPULAN}

4.1 Melihat besarnya peluang potensi PLTM yang belum dibangun sementara studi kelayakan menunjukkan bahwa harga jual listrik Rp 656/kWh akan memperoleh IRR > $20 \%$, Payback Period 5-6 tahun, maka investasi pembangunan PLTM sangat layak untuk dibangun.

4.2 Karena PLTM yang dibangun berbeda lokasi berbeda pula desainnya, maka ini merupakan peluang dan tantangan bagi para perancang teknologi. Tantangan bagi perancang teknik sipil meliputi hidrologi, bendung, intake berikut trash rack, kolam 
pengendap sedimen, saluran pembawa, kolam penenang. Bagi perancang teknik mesin meliputi pintu-pintu air, penstock, expansion joint, turbin dan stabilitasnya, getaran tubin dan pondasinya. Bagi kalangan perancang teknis listrik \& elektronika meliputi kualitas listrik yang keluar, kontrol dan transmission JTM. Bagi kalangan teknik material, bagaimana menemukan material yang murah dan kuat untuk penstock baik yang exposed maupun buried. Kemudian bagaimana memanage proyek ini dengan baik, baik sisi keuangan maupun konstruksi.

\section{REFERENSI}

[1] http://iklimkarbon.com

[2] Pusdatin ESDM 2010, Handbook ofEnergy \& Economic Statistics of Indonesia, INDONESIA Energy Outlook2010, pp.31-34, (2010).

[3] Pusdatin ESDM 2004, Statistik EkonomiEnergi Indonesia 2004, pp. 2-3, (2004).

[4] Menteri Energi dan Sumber Daya Mineral Republik Indonesia, Permen ESDM No : 05 Tahun 2009 Tentang Pedoman HargaPembelian Tenaga Listrik Oleh PT PLN (PESERO) dari Koperasi atau Badan UsahaLain, (2009).

[5] Menteri Energi dan Sumber Daya Mineral Republik Indonesia, Permen ESDM No: 31 Tahun 2009 Tentang Harga Pembelian Tenaga Listrik Oleh PT PLN (PERSERO) Dari Pembangkit Tenaga Listrik yang Menggunakan Energi Terbarukan Skala Kecil dan Menengahatau Kelebihan Tenaga Listrik, (2009).

[6] PT. Napal Melintang Energy Jakarta, Feasibility Study PLTMH NapalMelintang Kap : 2 × 290
KWKabupaten Kerinci Prop. Jambi, (2010).

[7] PT PESISIR HIDRO ENERGI JAKARTA, Feasibility Study PLTM Guntung ( $2 \times 2 M W)$, Kab. Agam Prop. Sumbar, (2010).

[8].

.http://kuliahitukeren.blogspot.c om/2011/03

[9] European Small Hydropower Association, Layman's Handbook on How to Develop a Small Hydro Site, Second Edition, (1998)

[10] US Dep. Of the Interior Bureau of Reclamation, Welded SteelPenstock, pp.14-18, (1986).

[11] EngineeringConsideration of Stress, StrainAnd Strength, McGraw-Hill Book Company,p.87, (1983).

[12] PT. Siteba Energy Jakarta, Design CriteriaPLTM-SITEBA 4, pp.VI 14- VI 15, (2009). 